\title{
Improved separations of phytoplankton pigments using temperature-controlled high performance liquid chromatography
}

\author{
Laurie Van Heukelem ${ }^{1}$, Alan J. Lewitus ${ }^{1, *}$, Todd M. Kana ${ }^{1}$, Neal E. Craft ${ }^{2}$ \\ ${ }^{1}$ Horn Point Environmental Laboratory, PO Box 775, Cambridge, Maryland 21613, USA \\ ${ }^{2}$ Southern Testing and Research Labs, Inc., 3709 Airport Dr., Wilson, North Carolina 27893, USA
}

\begin{abstract}
Varying the temperature of a polymeric $C_{18}$ high performance liquid chromatography (HPLC) column caused significant changes in elution profiles of carotenoid and chlorophyll (chl) pigment mixtures. High temperature operation $\left(60^{\circ} \mathrm{C}\right)$ was optimal for carotenoid separations, including the separation of zeaxanthin from lutein. Chlorophyll and chlorophyll derivative separations were optimal at a column temperature between 10 and $30^{\circ} \mathrm{C}$. A protocol is presented that achieves quantifiable resolution of all taxonomically important pigments tested by running the analysis at 2 temperatures: 10 and $60^{\circ} \mathrm{C}$. Of particular significance was the ability to separate divinyl chl a from monovinyl chl $a_{1}$ chl $c_{1}$ from chl $c_{2}$ and partial separation of $\mathrm{chl} c_{2}$ and MG 2,4-divinyl phaeoporphorin $a_{5}$ monomethyl ester. An example is given of the utility in separating chl c pigments, and lutein and zeaxanthin in natural phytoplankton samples.
\end{abstract}

KEY WORDS: Pigments - High performance liquid chromatography (HPLC) - Polymeric column - Temperature Phytoplankton - Divinyl chlorophyll a Chlorophyll $c$ - Carotenoids - Lutein - Zeaxanthin

\section{INTRODUCTION}

As the utility of high performance liquid chromatography (HPLC) in characterizing phytoplankton pigments becomes increasingly recognized, the need to establish HPLC protocols that are efficient and broadly applicable becomes more immediate. Advances in pigment separations by HPLC have centered on reversed phase protocols, largely because the commonly used extraction solvents, acetone and methanol, are incompatible with the non-water-miscible mobile phase used in normal phase HPLC. Recently, significant advances have been made in the phytoplankton pigment separation capability of reversed phase techniques which involve modifications of column type and/or mobile phase composition (e.g. Kleppel et al. 1988, Kohata et

\footnotetext{
- Present address: Baruch Marine Field Laboratory/USC PO Box 1630, Georgetown, South Carolina 29442, USA
}

al. 1991, Wright et al. 1991, Kraay et al. 1992, Van Heukelem et al. 1992, Goericke \& Repeta 1993). Despite these advances, no one protocol has been developed that can resolve all of the chlorophylls and carotenoids of chemotaxonomic significance to phytoplankton identification, as defined by Wright et al. (1991) and Millie et al. (1993).

One parameter rarely considered a variable in phytoplankton pigment HPLC analysis is column temperature. Although the importance of maintaining isothermal conditions for optimizing precision in HPLC is recognized, the role of temperature in separation selectivity for phytoplankton pigments has been largely unevaluated. The reason for this may be 2 -fold. Firstly, column compartments capable of precisely regulating temperature (i.e. with combined heating and cooling capabilities) are not standard items with most HPLC systems used in phytoplankton pigment research. Secondly, separation selectivity is weakly affected by temperature variation above $25^{\circ} \mathrm{C}$ when 
the popular monomeric $\mathrm{C}_{18}$ bonded phase columns are used (Sander \& Wise 1990). On the other hand, Sander \& Wise (1990) demonstrated that temperature could affect the separation selectivity of a polymeric $\mathrm{C}_{18} \mathrm{col}$ umn between temperatures of -20 and $80^{\circ} \mathrm{C}$. Craft et al. (1992) subsequently demonstrated the utility of polymeric column temperature control in manipulating separation selectivity of blood serum and food carotenoids. Therefore, a polymeric $\mathrm{C}_{18}$ column used in combination with an HPLC system that can precisely regulate the column temperature at subambient and/or above-ambient temperatures provides flexibility in manipulating separation selectivity independent of modifications in mobile phase composition or column type.

In a previous report (Van Heukelem et al. 1992), we demonstrated that the separation of several key pigments could be markedly improved by the relatively simple change from a monomeric to a polymeric $\mathrm{C}_{18}$ bonded phase column. However, the protocol, which used a setpoint temperature of $40^{\circ} \mathrm{C}$, could not quantifiably resolve some important pigment pairs, e.g. chlorophyllide $a$ and $c h l c_{3}$, diatoxanthin and lutein, monovinyl chl $a$ and divinyl chl $a$. Here, we evaluate the effect of column temperature on the separation selectivity of a Vydac 201TP polymeric column for these and several other phytoplankton pigments of chemotaxonomic importance. We demonstrate that resolution of all pigments tested can be achieved by alternating between 2 column temperatures; 10 and $60^{\circ} \mathrm{C}$. This is the first method capable of resolving all of the following pigment pairs using the same column and mobile phase; chlorophylls $c_{1}$ and $c_{2}$, lutein and zeaxanthin, and monovinyl chl a and divinyl chl $a$. It is also the first time that monovinyl chl a and divinyl chl a have been separated using a $\mathrm{C}_{18}$ bonded reversed phase column

\section{MATERIALS AND METHODS}

Sources of reference pigments. Reference pigments were extracted from algal monocultures obtained from the Provasoli-Guillard Center for Culture of Marine Phytoplankton, Bigelow Laboratory for Ocean Sciences ('CCMP'), or the Horn Point Environmental Laboratory, University of Maryland ('HP') culture collection. The phytoplankton species included Dunaliella tertiolecta CCMP (Chlorophyceae), Emiliania huxleyi CCMP373 (Prymnesiophyceae), Pelagococcus subviridis CCMP1429 (Chrysophyceae), Pycnococcus provasolii CCMP1203 (Prasinophyceae), Pyrenomonas salina (formerly Chroomonas salina) CCMP3C (Cryptophyceae), Gyrodinium uncatenum HP8901 (Dinophyceae), Phaeodactylum sp. HP9101 (Bacillario- phyceae), Prochlorococcus marinus CCMP1375 (Prochlorophyceae), and Tetraselmis suecica (Prasinophyceae). The first 5 species above were chosen based on the recommendations of Wright et al. (1991); see their Table 1 . The latter 4 species were selected because they contained the remaining pigments of diagnostic importance, and monocultures of these species were being maintained at Horn Point Environmental Laboratory at the time of the study. Astaxanthin was extracted from shrimp carapace obtained from a local grocery store. Canthaxanthin (Hoffman La Roche) was donated by Bruce Malone of Perdue Incorporated, Salisbury, MD, USA.

Field sampling. Water samples were obtained from a freshwater Florida lake (Lake Annie, Highlands County) on March 9, 1993. The samples were collected from the euphotic layer using Niskin bottles. For HPLC pigment analysis, aliquots (1.4 to $2.7 \mathrm{I}$ ) were filtered through a Whatman GF/C glass fiber filter or prefiltered in series through $5 \mu \mathrm{m}$ and $2 \mu \mathrm{m}$ Nuclepore filters, and then through a GF/F glass fiber filter. The glass fiber filters were folded in half, wrapped in aluminum foil, and stored first in liquid nitrogen, then in a freezer at $-80^{\circ} \mathrm{C}$. The sample was extracted (see below) and analyzed at column temperatures of 10,30 , and $60^{\circ} \mathrm{C}$. Aliquots were also taken for phytoplankton species identification and enumeration by light and epifluorescent microscopy. Some samples were fixed with either Bouin's or acid Lugol's solution, concentrated by settling chamber, and examined by light microscopy. Other samples were stained with primulin (Caron 1983), filtered through an Irgalan black-stained $3.0 \mu \mathrm{m}$ Nuclepore filter, and examined by epifluorescence microscopy. The $3.0 \mu \mathrm{m}$ Nuclepore filtrate was filtered through an Irgalan black-stained $0.2 \mu \mathrm{m}$ Nuclepore filter in order to identify and quantify picophytoplankton

Pigment extraction. Samples from algal monocultures were filtered onto either Whatman GF/F or GF/C filters, folded, wrapped in aluminum foil, and stored at $-80^{\circ} \mathrm{C}$. Filters were torn into pieces and ground in cold $100 \%$ acetone in a dimly lit room, after which the extract was held in a refrigerator $\left(4^{\circ} \mathrm{C}\right)$ for 20 min prior to filtration. Homogenates were clarified using an HPLC syringe cartridge filter (Gelman Acrodisc $13 \mathrm{CR}$ PTFE). The algal extracts were transferred to amber crimp-cap vials $(2 \mathrm{ml}$ ), and placed in the autosampler compartment held at 2 to $3^{\circ} \mathrm{C}$ until injection. Astaxanthin was prepared by grinding raw shrimp carapace in $100 \%$ acetone (G. Kleppel pers. comm.). To prepare the chlorophyllide-rich extract, a dense culture of Phaeodactylum sp. was collected on a GF/C filter and ground in cold acetone: water $(50: 50)$, following Jeffrey \& Hallegraeff (1987). The extract was then acidified with $10 \% \mathrm{HCl}$ to produce acidic chlorophyll 
degradation products. The acid was neutralized by the addition of $1.0 \mathrm{M}$ ammonium acetate during the injection cycle (R. Goericke pers. comm.).

High performance liquid chromatography. The HPLC was a fully automated Hewlett Packard Series II, $1090 \mathrm{M}$ with binary DR5 solvent delivery system, a built-in diode array detector (DAD) with $8 \mu$ flow cell, a temperature-controlled autosampler compartment and column oven compartment, and a programmable autoinjector (outfitted with a $250 \mu$ loop) capable of autoaddition and mixing. The autosampler compartment and column oven compartment were cooled with an RTE-100 recirculating refrigerated bath (Neslab). A Hewlett Packard 1046A, time-programmable fluorescence detector was installed after the DAD. The excitation (ex) and emission (em) wavelength setpoints were programmed for target analytes in the injected sample. Peak response was either enhanced or suppressed by selecting wavelengths specific to the pigments of interest (e.g, $440 \mathrm{~nm} \mathrm{ex,} 650 \mathrm{~nm}$ em for chlorophylls $c_{1}$ and $c_{2}$, or $425 \mathrm{~nm}$ ex, $670 \mathrm{~nm}$ em for monovinyl chl $a$ and its degradation products). All data were collected with a HP 79994A Pascal-based ChemStation. The reversed phase $\mathrm{C}_{18}$ column was a Vydac $201 \mathrm{TP}, 300 \AA$ pore size, $5 \mu \mathrm{m}$ particle size, $4.6 \mathrm{~mm}$ ID $\times$ $250 \mathrm{~mm}$ (Separations Group, Hesparia, California).

The binary solvent system of Mantoura \& Llewellyn (1983) was used with the exception that tetrabutylammonium acetate was omitted from Solvent A (Zapata et al. 1987). The solvents were formulated as follows: solvent $\mathrm{A}$ (methanol:0.5 $\mathrm{M}$ ammonium acetate, $80: 20$ ); solvent $B$ (methanol:acetone, $80: 20$ ). Pumping

Table 1. Examples of HPLC pumping gradients used at each column temperature. Solvent A was methanol:0.5 M ammonium acetate, $80: 20$; Solvent B was methanol:acetone, 80:20

\begin{tabular}{|cccrr|}
\hline $\begin{array}{l}\text { Temp. } \\
\left({ }^{\circ} \mathrm{C}\right)\end{array}$ & $\begin{array}{c}\text { Time } \\
(\mathrm{min})\end{array}$ & $\begin{array}{c}\text { Flow rate } \\
\left(\mathrm{ml} \mathrm{min}^{-1}\right)\end{array}$ & $\% \mathrm{~A}$ & $\% \mathrm{~B}$ \\
\hline 60 & 0.0 & 1.0 & 100 & 0 \\
& 5.0 & 1.0 & 60 & 40 \\
& 10.0 & 1.0 & 30 & 70 \\
& 13.0 & 1.0 & 30 & 70 \\
& 23.0 & 1.0 & 0 & 100 \\
& 24.0 & 1.5 & 0 & 100 \\
30 & & & & \\
& 0.0 & 1.0 & 100 & 0 \\
& 10.0 & 1.5 & 0 & 100 \\
& 17.0 & 1.5 & 0 & 100 \\
10 & & & & \\
& 0.0 & 1.0 & 100 & 0 \\
& 9.5 & 1.0 & 50 & 50 \\
& 17.0 & 1.0 & 25 & 75 \\
& 22.0 & 1.5 & 15 & 85 \\
& 27.0 & 2.0 & 0 & 100 \\
& 31.5 & 2.0 & 0 & 100 \\
\hline
\end{tabular}

gradients varied with column temperature, and several gradient protocols were used to achieve the desired resolution (Table 1). Using a programmable autoinjector, the acetone extracts were diluted with ammonium acetate immediately prior to injection; Wright et al. (1991) caution that the timing of the dilution and resultant extract polarity will affect hydrophobic pigment solubility, and advise that dilutions be conducted immediately prior to injection in order to minimize precipitation. It is possible that the concentration of water in the extract varied between samples (Bidigare 1991), because filter specifications were not consistent throughout the study (25 or $47 \mathrm{~mm}$ diameter GF/C or $\mathrm{GF} / \mathrm{F}$ filters), although $100 \%$ acetone was consistently used as the extraction solvent (to minimize activation of chlorophyllase; Jeffrey \& Hallegraeff 1987). The autoinjector was programmed to draw $63 \mu$ of sample, draw $37 \mu \mathrm{l}$ of $1.0 \mathrm{M}$ ammonium acetate, mix, wait $5 \mathrm{~min}$, and inject. All samples, including the ammonium acetate, were held in the temperature-controlled autosampler compartment at 2 to $3^{\circ} \mathrm{C}$. HPLC analyses were conducted at temperatures of $10,15,20,25,30$, $35,40,50$, and $60^{\circ} \mathrm{C}$. Column temperature varied by $< \pm 0.1^{\circ} \mathrm{C}$ from the setpoint.

Pigment identification. The identification of pigments in algal cultures was based on a comparison of our observed in-line DAD spectra (350 to $600 \mathrm{~nm}$ ) and $\%$ III/II ratios ${ }^{1}$ (Ke et al. 1970) with published values (Kohata et al. 1991, Wright et al. 1991) (Table 2). Selected pigments were individually fractioncollected, transferred to $100 \%$ acetone, and characterized in terms of absorbance spectra (350 to $750 \mathrm{~nm}$, Hitachi 3110 scanning spectrophotometer). The \% III/I and II/I ratios of these pigments were compared to previously published values (Jeffrey \& Wright 1987 , Wright \& Jeffrey 1987, Kraay et al. 1992).

Resolution. Resolution between pigments was quantified based on retention times and peak widths, following Kohata et al. (1991) and as described in Van Heukelem et al. (1992).

\section{RESULTS}

The effect of column temperature on the resolution of phytoplankton pigments was evaluated in 3 ways.

\footnotetext{
$1 \%$ III/II (as defined by Ke et al. 1970) is calculated on 3fingered carotenoid and xanthophyll spectra, where III is the absorbance maximum of the peak of highest wavelength and II is the absorbance maximum of the middle finger. The minimum absorbance value between peaks II and III (the trough) subtracted from each absorbance peak and the (III-trough)/ (II-trough) value is calculated and expressed as a percentage
} 
Table 2. Pigments from standard cultures showing in-line DAD spectra (wavelength range 350 to 600 nm) visible absorption maxima and peak ratios in HPLC eluant and $100 \%$ acetone, and retention times (min) from coinjections of selected algal cultures at 10 or $60^{\circ} \mathrm{C}$. Range of observed absorption maxima is presented in the cases where spectra varied among injections or species. Wavelengths of absorption shoulders are given in parentheses. Peak ratios are expressed in decimal form as the ratio of Soret band to red region maxima (for chlorophylls) or in percentage form as the ratio of tertiary to secondary (III/II) absorbance peaks (for carotenoids), following Ke et al. (1970). NA: not available

\begin{tabular}{|c|c|c|c|c|c|c|c|c|}
\hline \multirow[t]{3}{*}{ No. } & \multirow[t]{3}{*}{ Pigment } & \multirow[t]{3}{*}{ Source $^{a}$} & \multicolumn{2}{|c|}{$\longrightarrow$ Eluant $\longrightarrow$} & \multicolumn{2}{|c|}{ Acetone } & \multirow{2}{*}{\multicolumn{2}{|c|}{$\begin{array}{l}\text { Retention } \\
\text { time (min) }\end{array}$}} \\
\hline & & & \multirow{2}{*}{$\begin{array}{l}\text { Absorption } \\
\text { maxima }(\mathrm{nm})\end{array}$} & \multirow{2}{*}{$\begin{array}{l}\text { Peak } \\
\text { ratio }\end{array}$} & \multirow{2}{*}{$\begin{array}{l}\text { Absorption } \\
\text { maxima (nm) }\end{array}$} & \multirow{2}{*}{$\begin{array}{l}\text { Peak } \\
\text { ratio }\end{array}$} & & \\
\hline & & & & & & & $60^{\circ} \mathrm{C}$ & $10^{\circ} \mathrm{C}$ \\
\hline 1 & $\mathrm{Chl} c_{3}$ & A & $457,591, \mathrm{NA}$ & & & & 3.86 & 12.38 \\
\hline 2 & Chlorophyllide $a$ & $\mathrm{~K}, \mathrm{I}$ & 431, NA, NA & & & & 4.24 & 8.93 \\
\hline 3 & $\mathrm{Chl} c_{1}$ & $\mathrm{~B}, \mathrm{C}$ & $440-441,583, N A$ & & $446,579,629$ & $\begin{array}{l}6.5(\mathrm{III} / \mathrm{I}) \\
0.8(\mathrm{II} / \mathrm{I})\end{array}$ & 4.67 & 12.85 \\
\hline 4 & MG 2,4 D & $\mathrm{F}$ & 4.39, NA, NA & & & & 4.67 & 13.75 \\
\hline $4 a$ & MG 2, 4 D-like & $\mathrm{D}$ & 439 & & & & 4.67 & \\
\hline 5 & $\mathrm{Chl} c_{2}$ & $A, B, C, H$ & $445-447,583$ & & $450,583,631$ & $\begin{array}{c}10.8(\mathrm{III} / \mathrm{I}) \\
1.0(\mathrm{II} / \mathrm{I})\end{array}$ & 4.67 & 14.02 \\
\hline 6 & Peridinin & $\mathrm{B}$ & 471 & & 475 & & 5.67 & \\
\hline 7 & 19'-butanoyloxyfucox. & $\mathrm{G}$ & 445,467 & $19 \%$ & & & 6.37 & \\
\hline 8 & Fucoxanthin & $\mathrm{C}$ & $451,(465)$ & & 448,469 & $2 \%$ & 6.90 & \\
\hline 9 & 19'-hexanoyloxyfucox. & A & 447,469 & $14 \%$ & & & 7.28 & \\
\hline 10 & Neoxanthin & $E, F, I$ & $413,435-437,465$ & $90 \%$ & & & 7.61 & \\
\hline 11 & Prasinoxanthin & $\mathrm{F}$ & 455 & & & & 8.03 & \\
\hline 12 & Violaxanthin & E, I & $415,439,469$ & $94 \%$ & & & 8.42 & \\
\hline 13 & Unknown carotenoid & $\mathrm{B}$ & $417,441,469$ & $92 \%$ & & & 8.69 & \\
\hline 14 & Astaxanthin-like & $\mathrm{F}$ & 475 & & & & 8.88 & \\
\hline $14 \mathrm{a}$ & Astaxanthin & & $473-479$ & & & & 8.88 & \\
\hline 15 & Diadinoxanthin & $\mathrm{B}, \mathrm{C}$ & $(425), 445,475$ & $62 \%$ & $(429), 449,479$ & $66 \%$ & 9.34 & \\
\hline 16 & Alloxanthin & $\mathrm{H}$ & $(431), 451,481$ & $42 \%$ & $(435), 455,485$ & $46 \%$ & 10.17 & \\
\hline 17 & Unknown carotenoid & $\mathrm{H}$ & $(425), 445,475$ & $65 \%$ & & & 10.37 & \\
\hline 18 & Diatoxanthin & $\mathrm{C}$ & $(431), 451,479$ & $37 \%$ & $(434), 455,484$ & $40 \%$ & 10.55 & \\
\hline 19 & Lutein & I, E & $(424), 445-447,473$ & $66 \%$ & $426,448,476-477$ & $61 \%$ & 10.75 & \\
\hline 20 & Zeaxanthin & $\mathrm{D}$ & $(429), 451,477$ & $32 \%$ & 456,481 & $39 \%$ & 10.93 & \\
\hline 21 & Canthaxanthin & & 477 & & 473 & & 11.55 & \\
\hline 22 & Chl $b$ & $E, F, I$ & 467 & & & & 12.34 & 21.81 \\
\hline 23 & Divinyl chl $b$ & $\mathrm{D}$ & 477 & & & & 12.34 & \\
\hline 22 & Crocoxanthin & $\mathrm{H}$ & $(425), 445,475$ & $61 \%$ & & & 13.26 & \\
\hline 25 & Chl $a$ allomer & $\mathrm{K}$ & $425, \mathrm{NA}, \mathrm{NA}$ & & & & & 22.96 \\
\hline 26 & Chl a & All but D & 431, NA, NA & & & & 13.90 & 24.85 \\
\hline 27 & Divinyl chl a & $D$ & $441, N A, N A$ & & & & 13.90 & 25.17 \\
\hline 28 & Chl a-like & $\mathrm{K}$ & 431 & & & & 12.62 & \\
\hline 29 & Non-polar chl c-like & A & 457,587 & & & & 12.85 & \\
\hline 30 & Non-polar chl c-like & A & 457.587 & & & & 12.95 & \\
\hline 31 & $\alpha$-Carotene & $D, H, L$ & $(422), 445,473-475$ & $61 \%$ & 449,476 & $73 \%$ & 18.32 & \\
\hline 32 & $\beta$-Carotene & B & $(430), 451,477$ & $21 \%$ & 454,481 & $26 \%$ & 18.63 & \\
\hline 33 & Phaeophorbide a & $\mathrm{M}$ & $(407), 507,537$ & & & & 7.75 & 13.75 \\
\hline $\begin{array}{l}{ }^{\star} \text { Sol } \\
(E) \\
\text { sut } \\
\text { Bio }\end{array}$ & $\begin{array}{l}\text { urces: (A) Emiliania hu } \\
\text { Dunaliella tertiolecta, } \\
\text { cica, (J) shrimp carapac } \\
\text { Chemika, (M) source ' } \mathrm{K}\end{array}$ & $\begin{array}{l}\text { F) Pycnococ } \\
\text { e, (K) Phaeo } \\
\text { acidified w }\end{array}$ & $\begin{array}{l}\text { Gyrodinium uncaten } \\
\text { ccus provasolii, (G) Pel } \\
\text { odactylum extracted in } \\
\text { vith } 10 \% \mathrm{HCl} \text { for phae }\end{array}$ & $\begin{array}{l}\text { lagococ } \\
50.50 \text { a } \\
\text { ophorb }\end{array}$ & $\begin{array}{l}\text { odactylum sp., (D } \\
\text { oviridis, (H) Pyreno } \\
\text { water for chloroph }\end{array}$ & $\begin{array}{l}\text { Prochlo } \\
\text { monas sa } \\
\text { hyllide a, }\end{array}$ & $\begin{array}{l}\text { aus } n \\
\text { Tett } \\
\text { ka Cl }\end{array}$ & $\begin{array}{l}\text { rinus, } \\
\text { elmis } \\
\text { nika- }\end{array}$ \\
\hline
\end{tabular}

First, resolution of pigments from algal monocultures was tested at several temperatures. From these results, temperatures of 10,30 , and $60^{\circ} \mathrm{C}$ were selected for further analyses because the separation selectivity was widely disparate at these temperatures, and separation of closely eluting pigments of diagnostic importance could be achieved at each temperature. Secondly, monoculture extracts were combined such that pig- ments were co-injected in similar concentrations. HPLC analysis on various combinations of pigment mixtures was conducted at 10,30 , or $60^{\circ} \mathrm{C}$, and resolution of pigments was determined from the chromatograms. Finally, HPLC analyses at 10,30 , and $60^{\circ} \mathrm{C}$ were conducted on lake samples in order to examine the effectiveness of temperature manipulations in resolving pigments from natural waters. 


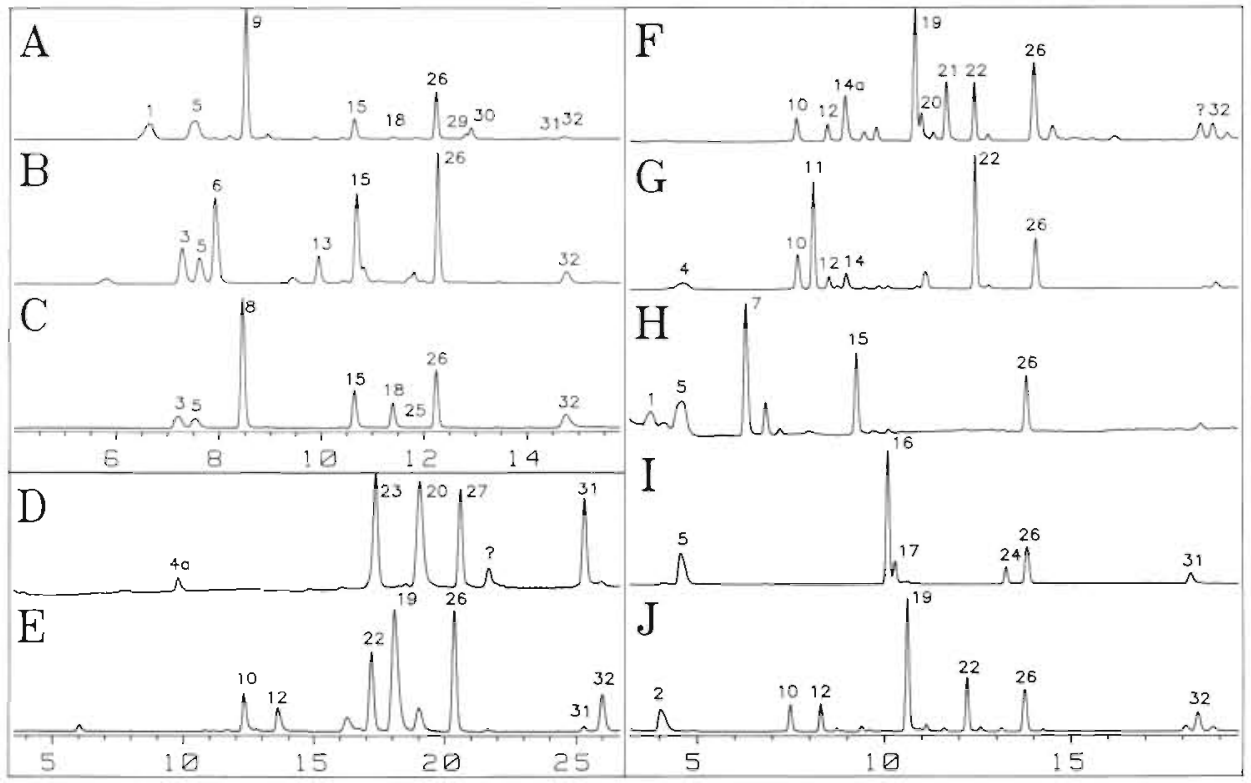

Fig. 1. High performance liquid chromatograms of acetone extracts from monocultures of (A) Emiliania huxleyi, (B) Gyrodinium uncatenum, (C) Phaeodactylum sp., (D) Prochlorococcus marinus, (E) Dunaliella tertiolecta, (F) Dunaliella tertiolecta spiked with astaxanthin and canthaxanthin, (G) Pycnococcus provasolii, (H) Pelagococcus subviridis, (I) Pyrenomonas salina, and (J) Tetraselmis suecica. Peak numbers correspond to pigments listed in Table 2 . Chromatograms $\mathrm{A}$ to $\mathrm{C}$ were analyzed at $30^{\circ} \mathrm{C}, \mathrm{D}$ and $\mathrm{E}$ at $20^{\circ} \mathrm{C}$, and $\mathrm{F}$ to $\mathrm{J}$ at $60^{\circ} \mathrm{C}$. Peak numbers are omitted where the signal was too weak to obtain in-line DADS. ? in F indicates the coelution of an unidentified carotenoid with $\alpha$-carotene

\section{Monocultures}

Algal monocultures of 9 species spanning 8 classes were evaluated for pigment composition at several column temperatures. Pigment signatures from the temperature which yielded the most information regarding the chemotaxonomically important pigments per culture are shown in Fig. 1

Comparison of the $60^{\circ} \mathrm{C}$ analyses of monoculture pigment extracts with analyses at other temperatures indicated that separation selectivity was highly dependent on column temperature. For example, in Gyrodinium uncatenum extracts, chlorophylls $c_{1}$ and $c_{2}$ coeluted at $60^{\circ} \mathrm{C}$, but were baseline-resolved at 30 and $20^{\circ} \mathrm{C}$ (Fig. 2A). However, although a decrease in temperature improved separation of chlorophylls $C_{1}$ and $c_{2}$, it decreased the separation between chl $c_{2}$ and peridinin (e.g. chl $c_{2}$ and peridinin coelute at $20^{\circ} \mathrm{C}$ ). Thus, temperature had a selective effect on the retention ability of the polymeric column for these pigments (e.g. lowering the temperature increased the retention time of chl $c_{2}$ to a much greater extent than that of peridinin, causing a merging of the pigments). In some cases, the selective effect of temperature on pigment retention resulted in reversals in pigment elution order. For example, in Dunaliella tertiolecta extracts, the magnitude of change in retention time with temperature was so much greater with lutein or zeaxanthin than

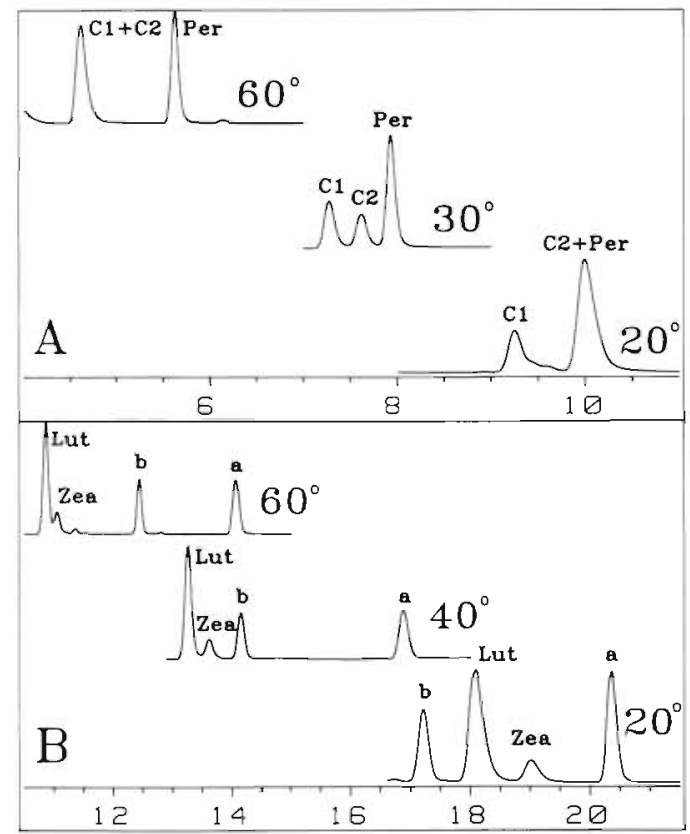

Fig. 2. High performance liquid chromatograms of (A) Gyrodinium uncatenum, and (B) Dunaliella tertiolecta extracts showing effects of column temperature $\left({ }^{\circ} \mathrm{C}\right)$ on resolution and retention time of chlorophylls $c_{1}(\mathrm{C} 1)$ and $c_{2}(\mathrm{C} 2)$, peridinin (Per), lutein (Lut), zeaxanthin (Zea), and monovinyl chlorophylls $b$ (b) and $a(a)$ 


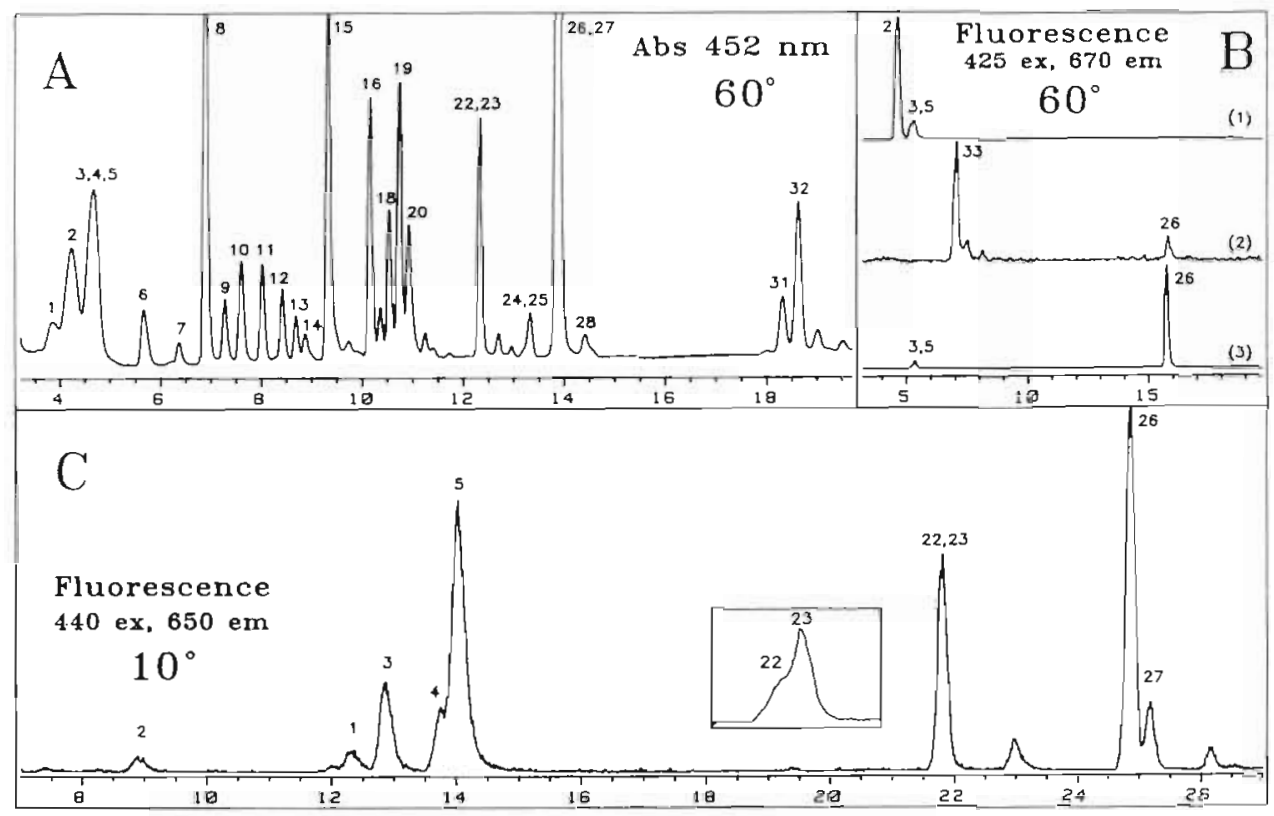

Fig. 3. High performance liquid chromatograms of acetone-extracted pigment mixtures injected at 60 or $10^{\circ} \mathrm{C}$. Peak numbers refer to pigments listed in Table 2. (A) Absorbance $\left(452 \mathrm{~nm}\right.$ ) signal at $60^{\circ} \mathrm{C}$ of combined extracts from Emiliania huxleyi, Pycnococcus provasolii, Tetraselmis suecica, Gyrodinium uncatenum, Pelagococcus subviridis, Phaeodactylum sp., Pyrenomonas salina, and Prochlorococcus marinus. (B) Fluorescence (425 nm excitation, $670 \mathrm{~nm}$ emission) signal at $60^{\circ} \mathrm{C}$ of (1) Phaeodactylum sp. extracted in 50:50 acetone:water to induce production of chlorophyllide $a_{1}(2)$ the above Phaeodactylum sp. extract acidified for phaeophorbide a production, and (3) Isochrysis sp. extract containing pigments common to both of the above extracts. (C) Fluorescence (440 nm excitation, $650 \mathrm{~nm}$ emission) signal at $10^{\circ} \mathrm{C}$ of combined extracts from Emiliania huxleyi, Pycnococcus provasolii, Gyrodinium uncatenum, and Prochlorococcus marinus. Inset shows the partial separation of monovinyl chl $b$ and divinyl chl $b$ when both pigments are present in similar amounts

with monovinyl chl $b$ that the elution order of the carotenoids and monovinyl chl $b$ were reversed between 40 and $20^{\circ} \mathrm{C}$ (Fig. 2B).

\section{Mixed algal extracts}

In HPLC analyses of mixed algal extracts run at $60^{\circ} \mathrm{C}$, the resolution between all chemotaxonomically important carotenoids was $\geq 1.0$ (Fig. 3A, Table 3), indicating that, when co-occurring, these pigments are identifiable and quantifiable at this temperature Included are diatoxanthin and lutein, which coeluted at $40^{\circ} \mathrm{C}$ (Van Heukelem et al. 1992). It should be noted, however, that an unidentified carotenoid coeluted with $\alpha$-carotene in extracts of Tetraselmis sueica and Dunaliella tertiolecta at $60^{\circ} \mathrm{C}\left(\mathrm{Fig} .1 \mathrm{~F}\right.$ ), but not at $30^{\circ} \mathrm{C}$ (data not shown). Phaeophorbide a can be resolved at $60^{\circ} \mathrm{C}$ when fluorescence detection is used (Fig. 3B). Limitations of the chlorophyll analysis at $60^{\circ} \mathrm{C}$ include the inability to separate (1) chl $c_{1}, \mathrm{chl} c_{2}$, and MG 2,4divinyl phaeoporphorin $a_{5}$ monomethyl ester (MG 2,4D), (2) monovinyl chl $b$ and divinyl chl $b$, or (3) monovinyl chl $a$ and divinyl chl $a$. Also, chl $c_{3}$ coeluted with an unidentified carotenoid (from Gyrodinium uncatenum) in the mixed extract at $60^{\circ} \mathrm{C}$.

Three chlorophyllous pigment groups that were not completely separated at $60^{\circ} \mathrm{C}$ were baseline or quantifiably resolved at $10^{\circ} \mathrm{C}$ : (1) chl $c_{3}$ and chlorophyllide $a$, (2) chl $c_{1}$ and chl $c_{2}$, and (3) monovinyl chl $a$ and divinyl chl a (Figs. $3 \mathrm{C} \& 4$, Table 3 ). In addition, 2 groups that coeluted at $60^{\circ} \mathrm{C}$ were partially resolved at $10^{\circ} \mathrm{C}$ : (1) monovinyl chl $b$ and divinyl chl $b$, and (2) $\mathrm{MG} 2,4 \mathrm{D}$ and chl $c_{2}$ (Figs. $3 \mathrm{C}$ plus inset \& $4 \mathrm{~B}_{\text {, }}$ Table 3). Divinyl chl $a$ is resolvable at this temperature even when present in disproportionately low concentrations (e.g resolution between monovinyl chl $a$ and divinyl chl $a$ in mixed algal extracts was 1.0 ; Figs. $3 \mathrm{C} \&$ $4 \mathrm{~A}$, Table 3). Furthermore, although several carotenoids coeluted at $10^{\circ} \mathrm{C}$, in-line DAD spectra revealed that monovinyl chl $a$ and divinyl chl a were resolved and not effected by the presence of other pigments (data not shown). Monovinyl chl $b$ and divinyl chl $b$ were partially resolved at $10^{\circ} \mathrm{C}$, and this resolution depended on the presence of proportionately similar pigment concentrations (Fig. $3 \mathrm{C}$ plus inset).

The partial resolution of chl $c_{2}$ and $\mathrm{MG} 2,4 \mathrm{D}$ at $10^{\circ} \mathrm{C}$ is limited by the potential interference of early-eluting 
Table 3. Effect of column temperature on resolution of various pigment pairs. Resolution $(R)$ was measured based on peak height, and is expressed as no resolution $(-; R=0)$, partial resolution $(+; 0<R<1.0)$, quantifiable resolution $(++; 1.0 \leq R<1.5)$, or baseline resolution $(+++; R \geq 1.5)$. 19'-but: 19'- butanoyloxyfucoxanthin; 19'-hex: 19'-hexanoyloxyfucoxanthin

\begin{tabular}{|c|c|c|c|c|c|c|c|c|c|}
\hline \multirow{2}{*}{ Pigment pair } & \multicolumn{9}{|c|}{ Column temperature $\left({ }^{\circ} \mathrm{C}\right)$} \\
\hline & 10 & 15 & 20 & 25 & 30 & 35 & 40 & 50 & 60 \\
\hline Chl $c_{2}$ /peridinin & - & + & - & - & ++ & ++ & +++ & +++ & +++ \\
\hline $\mathrm{Chl} c_{2} /$ fucoxanthin & - & - & ++ & ++ & +++ & ++ & +++ & $++t$ & +++ \\
\hline Peridinin/19'-but & ++ & + & +++ & +++ & & & & & \\
\hline Fucoxanthin/19'-hex & - & - & ++ & +++ & & & & & \\
\hline $19^{\prime}$-hex/neoxanthin & +++ & +++ & ++ & +++ & & & & & \\
\hline Neoxanthin/prasinoxanthin & - & - & - & + & ++ & +++ & & & \\
\hline Alloxanthin/lutein & - & - & - & + & + & +++ & +++ & +++ & \\
\hline Diatoxanthin/lutein & ++ & ++ & + & - & - & + & ++ & & \\
\hline Lutein/zeaxanthin & +++ & +++ & +++ & ++ & ++ & ++ & & & \\
\hline Lutein/chl $b$ & +++ & +++ & - & + & +++ & +++ & $t++$ & +++ & \\
\hline Zeaxanthin/chl $b$ & ++ & +++ & +++ & + & + & +++ & +++ & +++ & \\
\hline$\alpha$-Carotene $/ \beta$-carotene & +++ & +++ & +++ & ++ & ++ & ++ & ++ & ++ & ++ \\
\hline Crocoxanthin/chl a & +++ & +++ & ++ & - & ++ & +++ & +++ & & \\
\hline Chl $c_{3} /$ chlorophyllide $a$ & +++ & +++ & +++ & +++ & + & + & & & \\
\hline Chl $c_{1} / \mathrm{chl} c_{2}$ & +++ & ++ & +++ & ++ & ++ & ++ & + & - & - \\
\hline MG 2,4D/phaeophorbide $a$ & - & +++ & $+t+$ & & & & & & \\
\hline $\mathrm{MG} 2,4 \mathrm{D} / \mathrm{chI} \mathrm{c}_{2}$ & + & + & + & - & - & - & - & - & - \\
\hline Chl $b$ /divinyl chl $b$ & + & - & - & - & - & & & & \\
\hline $\mathrm{Chl}$ a/divinyl chl a & ++ & + & + & - & - & - & - & - & - \\
\hline
\end{tabular}

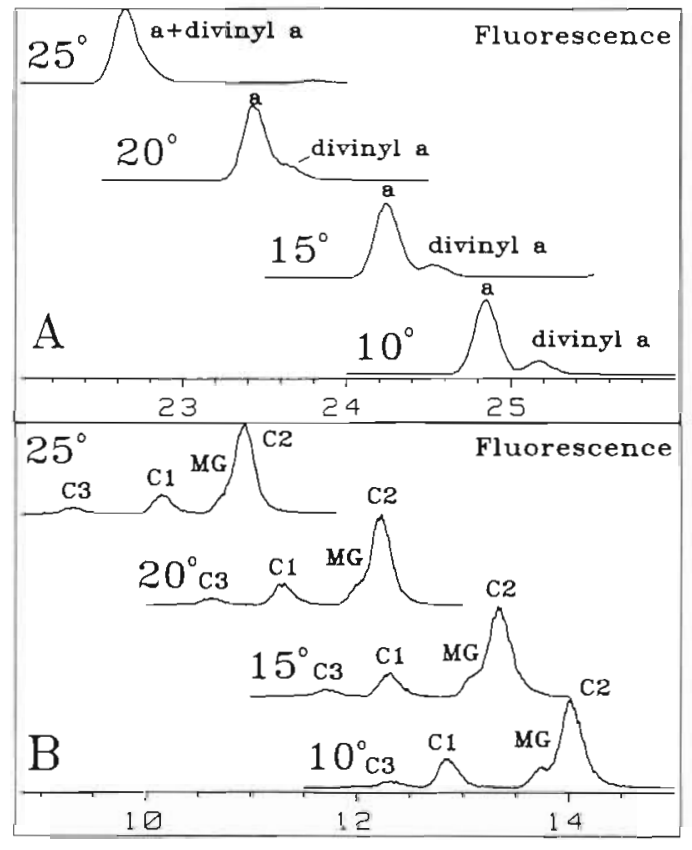

Fig. 4. High performance liquid chromatograms with fluorescence detection ( $440 \mathrm{~nm}$ excitation, $650 \mathrm{~nm}$ emission) of combined extracts from Prochlorococcus marinus, Gyrodinium uncatenum, Emiliania huxleyi, and Pycnococcus provasolii showing effects of column temperature $\left({ }^{\circ} \mathrm{C}\right)$ on separation of (A) monovinyl chl a (a) and divinyl chl a (divinyl a), and (B) MG 2,4D (MG) and chlorophylls $c_{1}(\mathrm{C} 1), c_{2}(\mathrm{C} 2)$, and $c_{3}(\mathrm{C} 3)$ carotenoids with chl $c_{2}$ (e.g. fucoxanthin or peridinin; Table 3). In the presence of these carotenoids, fluorometric detection must be used to selectively detect chl $c_{2}$ and $M G 2,4 \mathrm{D}$ at temperatures $\leq 25^{\circ} \mathrm{C}$ (e.g. Figs. 3C \& 4B). However, an additional problem is the potential coelution of phaeophorbide $a$ and MG 2,4D at $10^{\circ} \mathrm{C}$ (Table 3 ), and it is necessary to use fluorescence detector wavelength suppression to discriminate between these pigments (see 'Natural samples' section).

\section{Natural samples}

The utility of column temperature adjustments in determining the pigment composition of natural phytoplankton populations is illustrated in Fig. 5. The presence of taxonomically important carotenoids (e.g. zeaxanthin, fucoxanthin, violaxanthin, lutein, diadinoxanthin, and neoxanthin) and monovinyl chl $b$ are indicated in the $60^{\circ} \mathrm{C}$ chromatogram (Fig. 5A). Peak identities were confirmed by pooling extracts of the same size fraction, concentrating by solid phase extraction, reinjecting at $60^{\circ} \mathrm{C}$, and comparing in-line $\mathrm{DAD}$ spectra and retention times with pigments from algal reference cultures. Analysis at this temperature could not discriminate between chl $c_{1}$, chl $c_{2}$, and MG 2,4D.

The chlorophyllous pigments in Lake Annie samples were further detailed at lower temperatures. First, all 


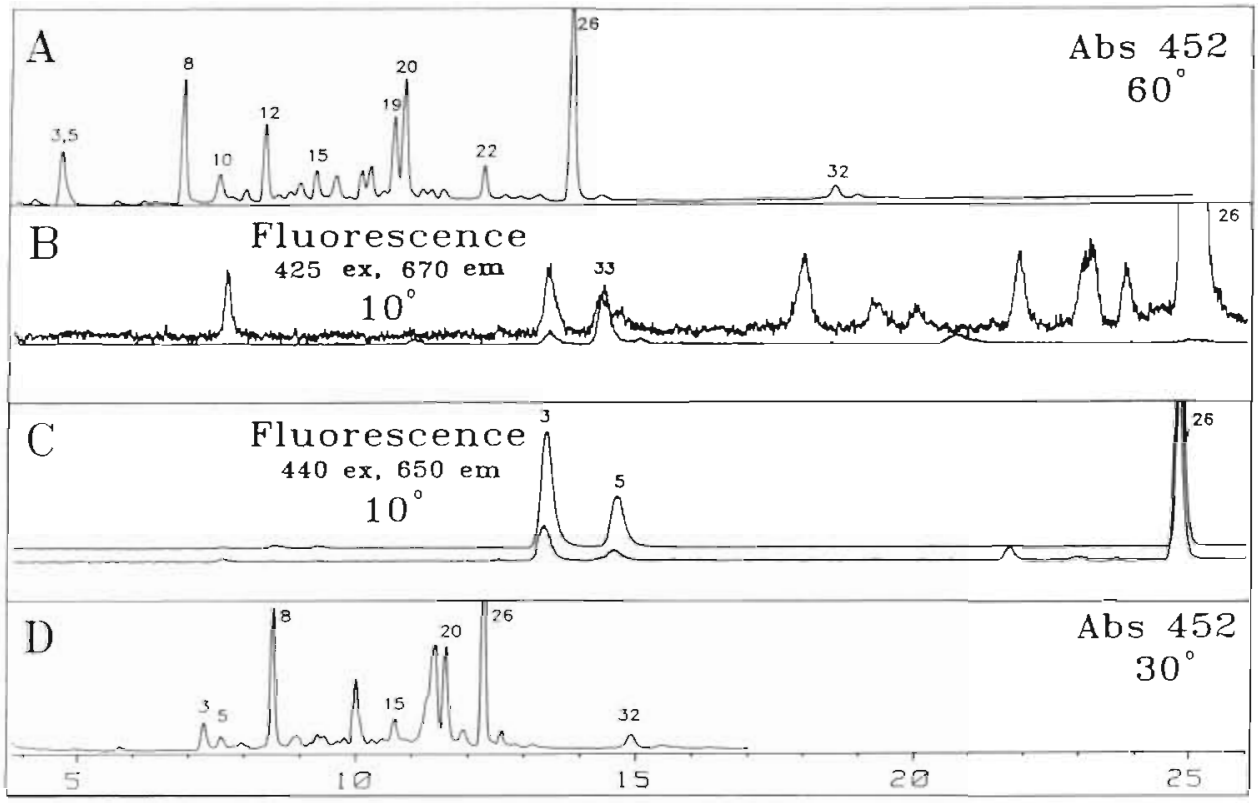

Fig. 5. HPLC phytoplankton pigment analyses from. Lake Annie (Florida, USA) water samples. Peak numbers correspond to pigments listed in Table 2. (A) Absorbance $\left(452 \mathrm{~nm}\right.$ ) signal at $60^{\circ} \mathrm{C}$ of Lake Annie extract. (B) Fluorescence (425 nm excitation, $670 \mathrm{~nm}$ emission) signals at $10^{\circ} \mathrm{C}$ of Lake Annie extract (upper chromatogram) and Phaeodactylum sp. extract treated with 50:50 acetone:water, and then acidified for phaeophorbide a production (Iower chromatogram). (C) Fluorescence (440 nm excitation, $650 \mathrm{~nm}$ emission) signals at $10^{\circ} \mathrm{C}$ of Lake Annie extract (lower chromatogram) and Gyrodinium uncatenum extract (upper chromatogram). (D) Absorbance (452 nm) signal at $30^{\circ} \mathrm{C}$ of Lake Annie extract

extracts were injected at $10^{\circ} \mathrm{C}$ (Fig. 5B, C). Specifically, we used this temperature to test for the presence of divinyl chl a (indicative of prochlorophytes; Chisholm et al. 1988, Goericke \& Repeta 1992), MG 2,4D, and/or chl $c_{3}$, and to determine the relative proportion of chlorophylls $c_{1}$ and $c_{2}$.

Divinyl chl a was not present in any of the samples, as determined by the comparison of retention times and in-line DAD spectra of samples with the algal reference culture, Prochlorococcus marinus (Fig. 5B). Because the fluorometer was set for maximum monovinyl chl a response in the evaluation of samples for the presence of divinyl chl a $(425 \mathrm{~nm}$ ex, $670 \mathrm{~nm}$ em), the response of chlorophylls $c_{1}$ and $c_{2}$ was suppressed in these injections, while the phaeophorbide $a$ peak, which elutes with the same retention time as MG 2,4D, was enhanced.

It was necessary to make subsequent injections at $10^{\circ} \mathrm{C}$ with the fluorometer optimized for chl $\mathrm{c}$ detectability (440 $\mathrm{nm}$ ex, $650 \mathrm{~nm}$ em) to elucidate the identity of the peak seen at the phaeophorbide $a / \mathrm{MG}$ $2,4 \mathrm{D}$ retention time, and to evaluate the presence of chlorophylls $c_{1}$ and $c_{2}$ (Fig. 5C). Because phaeophorbide a fluorescence is suppressed at these wavelengths, the absence of a signal at the phaeophorbide a/MG 2,4D retention time in Fig. 5C indicates that the degradation product contributed to the peak in Fig. 5B, but not MG 2,4D. Chl $c_{3}$, which is clearly resolved from other pigments at this temperature on both the fluorometer and absorbance detector, was absent from this sample. This chromatogram also indicated that chlorophylls $c_{1}$ and $c_{2}$ were both present, with the former pigment relatively more abundant than the latter (the peak height ratio of chl $c_{1}$ to chl $c_{2}$ was 3.2 in this $\mathrm{GF} / \mathrm{C}$ filter extract). Because fucoxanthin coeluted with $\mathrm{chl} c_{2}$ at $10^{\circ} \mathrm{C}$, the verification of the identity of chl $c_{2}$ by inline DAD spectra was not possible at this temperature. For this purpose, the extract was reinjected at $30^{\circ} \mathrm{C}$, where chlorophylls $c_{1}$ and $c_{2}$ elute freely on both detectors, and MG 2,4D, when present, is detectable on the upslope of the chl $c_{2}$ peak (Fig. 5D). The spectra of chlorophylls $c_{1}$ and $c_{2}$ matched those of the reference algal cultures. The similarity of reference and sample spectra on the upslope, apex, and downslope of the $\mathrm{chl} c_{2}$ peak indicated the presence of chl $c_{2}$, but not MG 2,4D, consistent with the results from the $10^{\circ} \mathrm{C}$ analyses presented above.

Microscopical examinations of fixed water samples confirmed the presence of phytoplankton indicated by the HPLC results. The relatively high contribution of zeaxanthin in the $60^{\circ} \mathrm{C}$ chromatogram (Fig. 5A) suggests the presence of cyanobacteria and/or chlorophytes, and both groups were prevalent in the sample. Cyanobacteria (e.g. Synechococcus spp., Merismope- 
dia spp.) were major constituents of the phytoplankton, comprising $28 \%$ of the total phototrophic biomass of the sample, while chlorophytes (e.g. Selenastrum sp., Staurastrum spp.) were also predominant components. The presence of chlorophytes also is consistent with the relatively high peaks in lutein and monovinyl chl $b$.

The relatively strong fucoxanthin signal in the $60^{\circ} \mathrm{C}$ chromatogram could indicate a number of algal groups. Based on microscopical evidence and the chromatograms at 30 and $10^{\circ} \mathrm{C}$, we suggest that dinoflagellates and chrysophytes are 2 potential contributors to this peak, but not diatoms, which were minor components of the phytoplankton population. Even though the dominant phototrophic microplankters at this depth were Peridinium spp., no peridinin was detected, suggesting that these dinoflagellates contributed to the fucoxanthin signal. Of the 3 Peridinium species examined for pigment composition by Jeffrey et al. (1975), 2 contained fucoxanthin instead of peridinin. Interestingly, these same species contained chl $c_{1}$ as well as chl $c_{2}$ (Jeffrey et al. 1975), suggesting that Peridinium spp. may be contributing to both chl ctypes detected in our 30 and $10^{\circ} \mathrm{C} \mathrm{HPLC}$ analyses (Fig. 5B to D).

Other potential contributors to the fucoxanthin signal are chrysophytes. Pico- and small nano-sized Synura sp. were identified in the sample, and colonies of these cells made up $5 \%$ of the phototrophic biomass (it was impossible to differentiate single cells of these species from other flagellates for quantitative purposes). These chrysophytes (or synurophytes; Andersen 1987) are unusual in that they contain chl $c_{1}$, but not chl $c_{2}$ (Andersen \& Mulkey 1983), and thus may account for the relatively high concentration of the former pigment in our sample (Fig. 5B to D). Further evidence that small chrysophytes were important here comes from the observation that fucoxanthin occurred in relatively high proportions in samples pre-filtered through 5.0 and $2.0 \mu \mathrm{m}$ Nuclepores, and then filtered onto a GF/F glass fiber filter (unpubl. data). Also, the proportion of chl $c_{1}$ to $\mathrm{chl} c_{2}$ was over twice as great in this $(<2 \mu \mathrm{m})$ filter extract as in the GF/C (whole water) filter extract (i.e. the $c_{1}: c_{2}$ peak height ratio was 6.6 in the former and 3.2 in the latter extract; Fig. 5C, unpubl. data). Altogether, the microscopical observations and HPLC analyses suggest that the unusually high ratio of chl $c_{1}$ to chl $c_{2}$ in Lake Annie was due to a relatively high contribution of pico- and small nano-sized Synura sp.

\section{DISCUSSION}

Several recent improvements in the HPLC separation of taxonomically important phytoplankton pigments have been achieved through manipulations in column type and mobile phase composition. Wright et al. (1991) resolved over 50 pigments using a ternary gradient system, while Kraay et al. (1992) used a different $C_{18}$ column to achieve baseline resolution of chlorophylls $c_{1}, c_{2}$, and $c_{3}$. Each method used a mobile phase containing methanol, acetonitrile, and ethyl acetate. Van Heukelem et al. (1992) used a polymerically synthesized $\mathrm{C}_{18}$ column with a modified Mantoura \& Llewellyn (1983) solvent system to achieve improved carotenoid resolution. Goericke \& Repeta (1993) demonstrated baseline resolution of chl a and divinyl chl a using a $\mathrm{C}_{8}$ column. To our knowledge, however, an HPLC method that allows quantifiable resolution between all major phytoplankton signature pigments (outlined in Wright et al. 1991 and Millie et al. 1993) has not been reported. In this study, we describe a protocol capable of quantitatively resolving all of the major signature pigments tested to date, using the same column and mobile phase throughout, but with variations in column temperature.

We observed that a resolution of 1.0 or greater is possible for most pigments examined, even when they are combined in a complex mixture and in disproportionate concentrations, as they might appear in a heterogeneous natural water sample. With a resolution of 1.0 , quantitative accuracy of $3 \%$ can be achieved when: (1) pigments differ in concentration by a factor $\leq 10^{3}$, and peak height is used to generate the calibration curve, or (2) pigment levels differ by a factor $\leq 9$, and peak area is used (Snyder \& Kirkland 1979). Where resolution is <1.0 (e.g. MG $2,4 \mathrm{D}$ and $\mathrm{chl} c_{2}$ or divinyl chl $b$ and monovinyl $(\mathrm{chl} b$ ), quantitative accuracy is compromised or impossible, and the partial resolution is useful only for commenting on the presence or absence of each component. Where resolution is $\geq 1.5$, the integration of the peak pair is considered baselineto-baseline (Poole \& Schuette 1984), and quantitative accuracy is not affected by relative pigment concentrations (Snyder \& Kirkland 1979).

We have demonstrated that several diagnostically important pigments can be quantifiably resolved using 2 successive injections at 60 and $10^{\circ} \mathrm{C}$, without changes in mobile phase or column type. We stress, however, that some key pigments were not evaluated (e.g. see Table 2 in Millie et al. 1993), and other temperatures may prove advantageous for resolving these pigments. Summarily, $60^{\circ} \mathrm{C}$ would suffice for quantitative resolution of all identified carotenoids tested here, monovinyl chlorophylls $a$ and $b$, chlorophyllide $a_{1}$ and phaeophorbide $a$. If the presence of prochlorophytes is in question, the $10^{\circ} \mathrm{C}$ analysis would be required for the separation of monovinyl chl a and divinyl chl a. Good separation of the chlorophylls $c_{1}$ and $c_{2}$ also could be obtained at $10^{\circ} \mathrm{C}$ by selective detection with fluorescence wavelengths set for phaeophorbide a 
suppression, while absorbance detection of chl $C_{2}$ would be useable at this temperature only if peridinin and fucoxanthin were absent. If the presence of prochlorophytes was not at issue, or the $60^{\circ} \mathrm{C}$ analysis suggested that they were absent (e.g. if no zeaxanthin or $\alpha$-carotene was detected), then the $30^{\circ} \mathrm{C}$ analysis would be an alternative to the $10^{\circ} \mathrm{C}$ analysis for characterizing chlorophylls $c_{1}, c_{2}$, and $c_{3}$.

We did not thoroughly examine the effects of different pumping gradients on the relationship between $k^{\prime}$ and resolution, and it is possible that further pumping gradient manipulations may decrease $k^{\prime}\left[k^{\prime}=\left(t_{r}-t_{0}\right) / t_{0}\right.$; where $t_{r}$ is retention time of retained compound and $t_{0}$ is retention time of unretained compound] and increase peak height without compromising resolution. We observed that column temperature affected peak height and peak width; e.g. broader, shorter peaks were associated with the lower temperature injections. This, coupled with a potential decrease in solubility at the lower temperatures, could diminish detectability relative to an injection at a higher temperature. Therefore, we suggest injecting at the highest temperature which will provide the desired resolution. Operating at temperatures above $60^{\circ} \mathrm{C}$, however, is not recommended (Vydac Separations Group column care and maintenance guide).

The HPLC protocol described here requires precise temperature control, a capability not universally available on HPLC systems. In fact, without temperature control, the advantage of polymeric over monomeric columns in improving resolution is lost (e.g. we observed severe deterioration in the resolution of several key pigment pairs at or near ambient temperatures, including chl $c_{2}$ and peridinin, neoxanthin and prasinoxanthin, alloxanthin and lutein, and monovinyl chl $b$ and lutein; Table 3). Although our HPLC was purchased with cooling capillaries already installed in the oven compartment, HPLC systems without this equipment can be modified for precise column temperature control. Sander \& Craft (1990) describe a device which can both heat and cool the column with precision only slightly less than what we experienced with our system $\left( \pm 0.2^{\circ} \mathrm{C}\right)$. Given its ease of application and its potential for enhancing flexibility in pigment resolution and selectivity, temperature control capability may provide a more efficient alternative to manipulations of column type and/or mobile phase composition as a means of identifying and quantifying diverse suites of phytoplankton pigments.

Acknowledgements. We thank Garry Baptist and Lisa WestJohnsrud for providing selected phytoplankton cultures, Deborah Kennedy for technical assistance and Robert Shackelford of Hewlett Packard for assistance with instrumentation. We are grateful to the staff of Archbold Biological Station (Lake Placid, Florida) for equipment and facilities, Margaret
Hobson for technical assistance, and Robert Ulanowicz for support associated with Lake Annie sampling. Support for this research came from the National Science Foundation grants OCE-9012669 to T.M.K. and BSR-8814272 to Robert Ulanowicz, and from the Analytical Services Laboratory at HPEL. This is contribution number 2545 from the Center for Environmental and Estuarine Studies, University of Maryland System.

\section{LITERATURE CITED}

Andersen, R. A. (1987). Synurophyceae classis nov, a new class of algae. Am. J. Bot, 74: 337-353

Andersen, R. A., Mulkey, T. J. (1983). The occurrence of chlorophylls $c_{1}$ and $c_{2}$ in the Chrysophyceae. J. Phycol. 19: $289-294$

Bidigare, R. R. (1991). Analysis of algal chlorophylls and carotenoids. In: Hurd, D. C., Spencer, D. W. (eds.) Marine particles: analysis and characterization, Geophysical Monograph 63. American Geophysical Union, Washington, DC, p. 119-123

Caron, D. A. (1983). Technique for enumeration of heterotrophic and phototrophic nanoplankton, using epifluorescence microscopy, and comparison with other procedures. Appl. environ. Microbiol 46: 491-498

Chisholm, S. W., Olson, R. J., Zettler, E. R., Goericke, R., Waterbury, J, B., Welschmeyer, N. A. (1988). A novel, freeliving prochlorophyte abundant in the ocean euphotic zone. Nature 334: $340-343$

Craft, N. E., Wise, S. A., Soares, J. H. Jr (1992). Optimization of an isocratic high-perfomance liquid chromatographic separation of carotenoids. J. Chromatogr. 589: 171-176

Goericke, R., Repeta, D. J. (1992). The pigments of Prochlorococcus marinus: the presence of divinyl chlorophyll $a$ and $b$ in a marine procaryote. Limnol. Oceanogr. 37: 425-433

Goericke, R, Repeta, D. J. (1993). Chlorophylls $a$ and $b$ and divinyl chlorophylls $a$ and $b$ in the open subtropical North Atlantic Ocean. Mar. Ecol. Prog. Ser. 101: 307-313

Jeffrey, S. W., Hallegraeff, G. M. (1987). Chlorophyllase distribution in 10 classes of phytoplankton - a problem for chlorophyll analysis. Mar. Ecol. Prog. Ser. 35: 293-304

Jeffrey, S. W., Sielicki, M., Haxo, F. T. (1975). Chloroplast pigment patterns in dinoflagellates. J. Phycol. 11: 374-384

Jeffrey, S. W., Wright, S. W. (1987). A new spectrally distinct component in preparations of chlorophyll $c$ from the microalga Emiliania huxleyi (Prymnesiophyceae). Biochim. Biophys. Acta 894: 180-188

Ke, B., Imsgard, F., Kjøsen, H., Liaaen-Jensen, S. (1970). Electronic spectra of carotenoids at $77^{\circ} \mathrm{K}$. Biochim. Biophys. Acta 210: 139-152

Kleppel, G. S., Frazel, D., Pieper, R. E., Holliday, D. V. (1988). Natural diets of zooplankton off southern California. Mar. Ecol. Prog. Ser. 49: 231-241

Kohata, K., Watanabe, M., Yamanaka, K. (1991). Highly sensitive determination of photosynthetic pigments in marine in situ samples by high-performance liquid chromatography. J. Chromatogr. 558: 131-40

Kraay, G. W., Zapata, M., Veldhuis, M. J. W. (1992). Separation of chlorophylls $c_{1}, c_{2}$, and $c_{3}$ of marine phytoplankton by reversed-phase- $C_{18}$-high-performance liquid chromatography. J. Phycol. 28: 708-712

Mantoura, R. F. C., Llewellyn, C. A. (1983). The rapid determination of algal chlorophyll and carotenoid pigments and their breakdown products in natural waters by reversephase high performance liquid chromatography. Analyt. Chim. Acta 151: 297-314 
Millie, D. F., Paerl, H. W., Hurley, J. P. (1993). Microalgal pigment assessments using high-performance liquid chromatography: a synopsis of organismal and ecological applications. Can. J. Fish. Aquat. Sci. 50: 2513-2527

Poole, C. F., Schuette, S. A. (1984). Contemporary practice of chromatography. Elsevier Science Publishing, New York

Sander, L. C., Craft, N. E. (1990). Device for subambient temperature control in liquid chromatography. Analyt. Chem. 62: $1545-1547$

Sander, L. C., Wise, S. A. (1990). Evaluation of shape selectivity in liquid chromatography. LG-GC 8: 378-90

Snyder, L. R., Kirkland, J. J. (1979). Introduction to modern liquid chromatography, 2nd edn. John Wiley \& Sons, Inc., New York

Van Heukelem, L., Lewitus, A. J., Kana, T. M., Craft, N. E.

This article was presented by O. Holm-Hansen (Senior

Editorial Advisor), La Jolla, California, USA
(1992). High-performance liquid chromatography of phytoplankton pigments using a polymeric reversedphase $\mathrm{C}_{18}$ column. J. Phycol. 28: 867-872

Wright, S. W., Jeffrey, S. W. (1987). Fucoxanthin pigment markers of marine phytoplankton analysed by HPLC and HPTLC. Mar. Ecol. Prog. Ser. 38: 259-266

Wright, S. W., Jeffrey, S. W., Mantoura, R. F. C., Llewellyn, C. A., Bjørnland, T., Repeta, D., Welschmeyer, N. (1991) Improved HPLC method for the analysis of chlorophylls and carotenoids from marine phytoplankton. Mar. Ecol Prog. Ser. 77. 183-96

Zapata, M., Ayala, A. M., Franco, J. M., Garrido, J. L. (1987) Separation of chlorophylls and their degradation products in marine phytoplankton by reversed-phase high performance liquid chromatography. Chromatographia 23 $26-30$

Manuscript first received: July 7, 1993

Revised version accepted: July 28, 1994 